\title{
Expressão diferencial de proteínas do fungo Conidiobolus lamprauges cultivado em diferentes temperaturas
}

\author{
Differential expression of protein of the fungus Conidiobolus lamprauges \\ cultivated at different temperatures
}

\author{
Isabela de Godoy ${ }^{\mathrm{I}}$ Daphine Ariadne Jesus de Paula ${ }^{\mathrm{I}}$ Marcelo Marques da Silveira ${ }^{\mathrm{I}}$ \\ Laila Natasha dos Santos Brandão ${ }^{\mathrm{I}}$ Valéria Dutra ${ }^{\mathrm{I}}$ Luciano Nakazato $^{\mathrm{I*}}$
}

RESUMO

Para sobreviverem na temperatura corpórea de seu hospedeiro, os fungos patogênicos têm desenvolvido mecanismos moleculares importantes, como a expressão de proteínas relacionadas ao crescimento em altas temperaturas. Assim, o objetivo deste trabalho foi analisar o crescimento in vitro de Conidiobolus lamprauges em diferentes temperaturas e comparar o perfil de proteínas expressas através de eletroforese bidimensional (2D), em duas temperaturas distintas, sendo uma considerada baixa $\left(28^{\circ} \mathrm{C}\right)$ e alta $\left(37^{\circ} \mathrm{C}\right)$. Para análise do crescimento em diferentes temperaturas, cinco isolados de $\boldsymbol{C}$. lamprauges, oriundos de ovinos doentes, foram incubados a $20,25,30,35$ e $40^{\circ} \mathrm{C}$ e o crescimento radial foi medido a cada 24 horas. Para análise da expressão diferencial, realizou-se a extração de proteínas do fungo cultivado a $28^{\circ} \mathrm{C}$ e a $37^{\circ} \mathrm{C}$ por 48 horas. A média de crescimento radial dos isolados foi diferente nas temperaturas analisadas, sendo $35^{\circ} \mathrm{C}$ a melhor temperatura para crescimento em todas as amostras. A temperatura ótima ajustada variou entre $33,3^{\circ} \mathrm{C}$ a $34,8^{\circ} \mathrm{C}$. Os limites inferior e superior de inibição de crescimento foram $18^{\circ} \mathrm{C}$ e $42^{\circ} \mathrm{C}$, respectivamente. $\mathrm{Na}$ análise da expressão diferencial, foram encontrados 16 spots diferencialmente expressos, sete (7/16) estavam com expressão diminuída e nove $(9 / 16)$ com expressão aumentada a $37^{\circ} \mathrm{C}$, quando comparado a $28^{\circ} \mathrm{C}$. Além disso, oito spots estavam presentes apenas a $28^{\circ} \mathrm{C}$ e seis a $37^{\circ} \mathrm{C}$. Sugere-se que C. lamprauges produza um perfil de proteínas relacionadas à termorregulação desencadeado pela alta temperatura do hospedeiro.

Palavras-chaves: temperatura de crescimento, ovinos, proteína, Zigomiceto.

\section{ABSTRACT}

To survive at the body temperature of their hosts, pathogenic fungi have developed important molecular mechanisms, such as protein expression associated with growth at high temperatures. Thus, the aim of this study was to analyze the in vitro growth of Conidiobolus lamprauges at different temperatures and compare proteins expressed by two-dimensional electrophoresis (2D), for the pathogen cultivated at low $\left(28^{\circ} \mathrm{C}\right)$ and high $\left(37^{\circ} \mathrm{C}\right)$ temperatures. For the analysis of growth temperatures, five isolates of C. lamprauges from sick sheep were incubated at 20, 25, 30, 35 and $40^{\circ} \mathrm{C}$ and radial growth was measured every 24 hours. For the analysis of differential expression, protein extraction and twodimensional polyacrylamide gel electrophoresis were performed with C. lamprauges cultivated at $28^{\circ} \mathrm{C}$ and $37^{\circ} \mathrm{C}$ for 48 hours. The average radial growth was different at the temperatures tested, and $35^{\circ} \mathrm{C}$ was found to be the best growth temperature for all isolates. The optimum adjusted temperature ranged between $33.3^{\circ} \mathrm{C}$ and $34.8^{\circ} \mathrm{C}$. The upper and lower limits of growth inhibition were $18^{\circ} \mathrm{C}$ and $42^{\circ} \mathrm{C}$, respectively. Upon expression analysis, a total of 16 spots were differentially expressed, seven (7/16) proteins were downregulated and nine (9/16) were over-expressed at $37^{\circ} \mathrm{C}$ compared to $28^{\circ} \mathrm{C}$. In addition, eight spots were present only at $28^{\circ} \mathrm{C}$ and six were present only at $37^{\circ} \mathrm{C}$. It is suggested that $\boldsymbol{C}$. lamprauges produces a profile of proteins that is related to thermoregulation triggered by the high temperature of the host.

Key-words: growth temperature, sheep, protein, Zygomycete.

\section{INTRODUÇÃO}

Conidiobolus coronatus, $C$. incongrus e $C$. lamprauges, pertencentes à ordem Entomophtorales (RIBES et al., 2000), são as principais espécies envolvidas na Conidiobolomicose. Esses fungos são capazes de causar micoses cutâneas e subcutâneas em humanos e animais (RIBES et al., 2000; BOABAID et al., 2008; KIMURA et al., 2011). A patogenia dessa enfermidade não está bem esclarecida. Os estudos estão voltados principalmente à virulência de Conidiobolus spp. como controle biológico de insetos

'Laboratório de Microbiologia Veterinária e Biologia Molecular, Universidade Federal de Mato Grosso (UFMT), 78060-900, Cuiabá, MT, Brasil. E-mail: lucnak@ufmt.br.*Autor para correspondência. 
(SHAH \& PELL, 2003), sendo a espécie C. coronatus a mais citada.

Microrganismos patogênicos são capazes de sobreviver na temperatura fisiológica do seu hospedeiro a fim de proliferar e causar a doença (KRAUS et al., 2004). Conidiobolus spp. tem ótimo crescimento a $37^{\circ} \mathrm{C}$ (RIBES et al., 2000). Cepas isoladas de humanos infectados crescem mais rapidamente a $37^{\circ} \mathrm{C}$ que aquelas isoladas do ambiente, sugerindo que a temperatura possa estar associada à produção de algum fator de virulência (RIBES et al., 2000).

A faixa ótima de temperatura varia entre as espécies e as mudanças térmicas podem causar alterações nas propriedades estruturais e fisiológicas dos organismos (RIBEIRO, 2010). Para se adaptar à temperatura corpórea do hospedeiro, microrganismos desenvolvem mecanismos moleculares importantes, como superexpressão ou repressão de genes, resultando na produção de proteínas e fatores transcricionais que possivelmente estão associados à patogenia da enfermidade e à virulência do fungo (ROSA E SILVA et al., 2008).

Uma forma de entender melhor o funcionamento dos genes é através da proteômica, a qual analisa o produto final do genoma. A identificação de proteínas pode auxiliar no entendimento de características relacionadas à patogênese da doença, em novos diagnósticos e tratamentos e vacinas (GALDOS-RIVEROS et al., 2010). Não há estudos na literatura que mostrem perfis proteicos e/ou identifiquem proteínas produzidas pelo Conidiobolus spp. na conidiobolomicose ovina e nem que relacionam o efeito da temperatura no comportamento de tal fungo a nível molecular. Assim, o objetivo deste trabalho foi caracterizar o crescimento do C. lamprauges em diferentes temperaturas e comparar, através da expressão diferencial de proteínas, o patógeno cultivado em duas temperaturas distintas, uma considerada baixa e outra alta, selecionadas após os resultados obtidos no experimento de caracterização do crescimento de C. lamprauges.

\section{MATERIAL E MÉTODOS}

Para a análise do crescimento em diferentes temperaturas, foram utilizados cinco isolados de $\boldsymbol{C}$. lamprauges M290/07 (INCQS 40316), M303/07 (INCQS 40317), M260/09 (INCQS 40315), M614/09 (INCQS 40319) e M446/10 (INCQS 40318), oriundos de ovinos doentes, caracterizados e confirmados pela técnica de PCR (PAULA et al., 2010) e mantidos no laboratório de Microbiologia Veterinária.
Os cinco isolados foram semeados em Agar Sabouraud Dextrose (SDA) 2\% e incubados a $37^{\circ} \mathrm{C}$ por sete dias. Após o cultivo, foi realizada a suspensão de esporos com auxílio de alça do tipo Drigalski em 3,0ml de solução estéril de Tween 80 a $0,01 \%(\mathrm{v} / \mathrm{v})$. A suspensão obtida foi lavada com água ultrapura estéril, centrifugada a 3354 x g por 17 minutos e o pellet ressuspendido em $1 \mathrm{ml}$ de água ultrapura estéril. Os esporos foram contados em câmera de Neubauer e diluídos até uma concentração de $10^{6}$ esporosmL $L^{-1}$.

No centro de cada placa de Petri $(14,0 \times 1,5 \mathrm{~cm})$ com SDA $2 \%$, foram inoculados $10 \mu 1$ ( $10^{4}$ esporos) da suspensão de esporos, sendo feitas triplicatas para cada isolado. As placas foram incubadas em cinco diferentes temperaturas $(20,25$, 30,35 e $40^{\circ} \mathrm{C}$ ) e o crescimento radial dos fungos foi medido a cada 24 horas, sendo realizado por meio de uma régua graduada. As medidas foram realizadas sempre no mesmo local de mensuração, até que os isolados atingissem a proximidade das bordas da placa de Petri, o que levou aproximadamente cinco dias. Os isolados foram também cultivados com $\pm 2^{\circ} \mathrm{C}$ $\left(18\right.$ e $\left.42^{\circ} \mathrm{C}\right)$ das temperaturas acima para detectar o limite inferior e superior de crescimento.

O delineamento experimental utilizado foi inteiramente casualizado, em que os tratamentos corresponderam às combinações dos cinco isolados de C. Iamprauges com as cinco condições de temperatura testadas, obtendo um total de 25 tratamentos. Cada tratamento foi composto por três repetições, sendo cada repetição correspondente a uma placa de Petri, totalizando 75 placas. Os dados foram submetidos à Análise de variância e as médias foram comparadas pelo teste de Scott-Knott, com nível de significância de 5\%.

Para a análise de expressão diferencial, o isolado INCQS 40316, anteriormente utilizado para análise de transcritos diferencialmente expressos (SILVA et al., 2012), foi cultivado em SDA 2\% e mantido em incubadora tipo B.O.D. (Química Nova) a 28 e $37^{\circ} \mathrm{C}$, por 48 horas. Após o cultivo, as amostras foram submetidas à extração de proteínas, segundo protocolo adaptado de WINTERS et al. (2008) e, posteriormente, homogeneizadas em tampão de extração gelado, suplementado com inibidores de proteases. A quantificação foi realizada pelo método de Bradford (BRADFORD, 1976).

Os géis bidimensionais (2-D) foram realizados segundo protocolo modificado de O'FARREL (1975) e RABILLOUD (1998), em triplicata. Amostras contendo aproximadamente $250 \mu \mathrm{g}$ de proteínas foram precipitadas com solução 
de TCA:Acetona (1:9), solubilizadas em tampão de reidratação e aplicadas em fitas Zoom $^{\circledR}$ Strip pH 3-10L (7cm, Bio-rad) para a realização da primeira dimensão. Após a focalização isoelétrica, realizada em sistema IPGRunner (Invitrogen), as fitas foram reduzidas com $1 \%$ de DTT e alquiladas em 2,5\% de iodoacetamida em tampão de equilíbrio (BJELLQVIST et al., 1993).

A segunda dimensão foi feita em gel de poliacrilamida, segundo LAEMMLI (1970), e corada por Nitrato de prata (WESTERMEIER \& NAVEN, 2002). As imagens dos géis foram capturadas e processadas em sistema de fotodocumentação (ChemiDoc $\mathrm{XRS}^{+}$, Bio-Rad). A análise quantitativa dos géis foi realizada por meio do software PDQuest 8.0.1 (Bio-Rad), adotando-se o método estatístico de regressão local para normalização dos spots.

\section{RESULTADOS E DISCUSSÃO}

Os isolados apresentaram diferenças significativas no seu crescimento radial quando comparados entre si em uma mesma temperatura e em diferentes temperaturas (Tabela 1). Dessa maneira, ocorreu um efeito significativo para a interação entre temperatura e crescimento dos isolados $(\mathrm{P}<0,0001)$, com nível de significância de $5 \%$. O teste de médias (Tabela 1) mostrou que o isolado INCQS 40319 apresentou a maior média em todas as temperaturas testadas. O isolado INCQS 40316, no entanto, apresentou um menor crescimento radial entre os isolados, independente da temperatura testada.

A análise do crescimento dos isolados em diferentes temperaturas demonstrou, por meio do teste de regressão, que os isolados apresentaram média de crescimento crescente nas temperaturas de 20 até $35^{\circ} \mathrm{C}$. A temperatura ótima de crescimento de cada isolado variou entre 33,3 a $34,8^{\circ} \mathrm{C}$ (Tabela 1), baseado na equação descrita para cada isolado. O crescimento foi inibido completamente quando incubado a 18 e $42^{\circ} \mathrm{C}$.

A maioria dos fungos de importância clínica apresenta temperatura ótima de isolamento e crescimento de 25 a $30^{\circ} \mathrm{C}$, mas, em alguns fungos subcutâneos e sistêmicos dimórficos, como Histoplasma capsulatum, Blastomyces dermatitidis e Sporothrix schenckii, é de $37^{\circ} \mathrm{C}$ (DISMUKES et al., 2003). Em alguns casos, a capacidade de crescimento de fungos acima de $40^{\circ} \mathrm{C}$ denomina-se termotolerância (WALKER \& WHITE, 2005).

Os resultados observados neste estudo estão de acordo com análises realizadas com Aspergillus flavus (GADGILE \& CHAVAN, 2010), as quais mostraram uma temperatura ótima de crescimento in vitro de $35^{\circ} \mathrm{C}$. WAINGANKAR et al. (2008) descreveram uma nova espécie, Conidiobolus thermophilus, o qual teve um ótimo desenvolvimento a $40^{\circ} \mathrm{C}$, sem importância clínica, mas com possíveis aplicações biotecnológicas.

Em relato de infecção causada por $\boldsymbol{C}$. lamprauges em um homem de 61 anos, tal fungo foi cultivado em cinco temperaturas distintas, sendo observado o maior diâmetro de crescimento a $36,5^{\circ} \mathrm{C}$ e cultura negativa a 45 e $50^{\circ} \mathrm{C}$ (KIMURA et al., 2011). Esses dados são diferentes dos obtidos neste estudo com isolados de ovinos doentes, cuja temperatura ótima ficou entre 33 e $35^{\circ} \mathrm{C}$, com a inibição do crescimento obtida a partir de $42^{\circ} \mathrm{C}$. As diferenças desses resultados podem estar associadas ao fato de as temperaturas utilizadas por KIMURA et al. (2011) terem um intervalo grande, não sendo testadas temperaturas como, por exemplo, $35^{\circ} \mathrm{C}$ e não ser realizada uma análise de regressão.

Em relação a organismos capazes de causar lesões no trato respiratório superior de ovinos,

Tabela 1 -Temperatura ótima estimada e valor médio para tamanho do halo de crescimento dos isolados de $\boldsymbol{C}$. Iamprauges, em diferentes temperaturas.

\begin{tabular}{|c|c|c|c|c|c|c|}
\hline \multirow{2}{*}{ Isolados } & \multicolumn{6}{|c|}{ - } \\
\hline & $20^{\circ} \mathrm{C}$ & $25^{\circ} \mathrm{C}$ & $30^{\circ} \mathrm{C}$ & $35^{\circ} \mathrm{C}$ & $40^{\circ} \mathrm{C}$ & $\mathrm{Est}^{*}\left({ }^{\circ} \mathrm{C}\right)$ \\
\hline INCQS 40316 & $13,33 \mathrm{~d}$ & $54,67 \mathrm{c}$ & $90,00 \mathrm{c}$ & $109,67 \mathrm{c}$ & $69,33 \mathrm{c}$ & 33,35 \\
\hline INCQS 40317 & $22,67 \mathrm{c}$ & $66,67 \mathrm{a}$ & $89,33 \mathrm{c}$ & $116,00 \mathrm{~b}$ & $86,67 \mathrm{a}$ & 34,15 \\
\hline INCQS 40315 & $31,33 b$ & $63,67 b$ & $95,33 b$ & $120,00 \mathrm{a}$ & $78,00 \mathrm{~b}$ & 33,72 \\
\hline INCQS 40319 & $36,00 \mathrm{a}$ & $66,00 \mathrm{a}$ & $100,67 \mathrm{a}$ & $122,67 \mathrm{a}$ & $83,67 a$ & 33,56 \\
\hline INCQS 40318 & $22,33 c$ & $61,33 b$ & $88,66 \mathrm{c}$ & $117,00 \mathrm{~b}$ & $84,67 \mathrm{a}$ & 34,86 \\
\hline
\end{tabular}

*Temperatura ótima estimada por regressão. Médias seguidas de mesma letra na coluna não diferem entre si pelo teste de Scott-knott a um nível nominal de significância de $5 \%$. 
houve discordância quando comparado a um estudo que analisou o efeito da temperatura no crescimento de Pythium insidiosum (KRAJAEJUN et al., 2010), sendo observada uma temperatura ótima entre 28 e $32^{\circ} \mathrm{C}$ e inibição do crescimento a 8 e $42^{\circ} \mathrm{C}$.

Embora C. lamprauges ocorra no mundo todo, a doença é comum em regiões de clima tropical e subtropical (CARRIGAN et al., 1992), onde a média de temperatura é consideravelmente alta, o que pode explicar a elevada faixa ótima de temperatura de crescimento encontrada neste estudo. Além disso, o fungo em questão parasita hospedeiros cujas temperaturas corporais são altas: $37^{\circ} \mathrm{C}$ (humano) e $39^{\circ} \mathrm{C}$ (ovinos), entre outros. Dessa forma, o microrganismo deve ser capaz de expressar genes relacionados à infecção, o que altera a regulação gênica e permite a adaptação ao hospedeiro a fim de causar a doença, como ocorre em Aspergillus fumigatus, Cryptococcus neoformans, Paracoccidioides brasiliensis.

$\mathrm{Na}$ análise de expressão diferencial, 51 spots foram encontrados na condição de $28^{\circ} \mathrm{C}$ e 49 spots a $37^{\circ} \mathrm{C}$, sendo 16 spots diferencialmente expressos, dos quais sete (7/16) estavam com expressão diminuída e nove $(9 / 16)$ com expressão aumentada a $37^{\circ} \mathrm{C}$, quando comparado a $28^{\circ} \mathrm{C}$ (Tabela 2). Além disso, oito spots estavam presentes apenas a $28^{\circ} \mathrm{C}$ e seis presentes apenas a $37^{\circ} \mathrm{C}$ (Figura 1$)$.

Em estudo de proteômica comparativa entre A. fumigatus e A. lentulus, observaram-se diferenças significativas de acordo com a temperatura de cultivo, sendo encontradas 20 proteínas superexpressas a

Tabela 2 - Relação dos spots obtidos pela análise proteômica diferencial de C. lamprauges, cultivado a 25 e $37^{\circ} \mathrm{C}$ através do software PDQuest 8.0.1 (Bio-Rad).

\begin{tabular}{|c|c|c|c|c|c|}
\hline SSP* & $\mathrm{Mr}(\mathrm{kDa})$ & $\mathrm{pI}$ & $28^{\circ} \mathrm{C}$ (intensidade) & $37^{\circ} \mathrm{C}$ (intensidade) & Razão $\left(37\right.$ vs $\left.28^{\circ} \mathrm{C}\right)$ \\
\hline 5515 & 59,33 & 8,59 & 13978303,0 & & \\
\hline 5404 & 43,73 & 7,55 & 2220747,8 & & \\
\hline 3702 & 114,14 & 5,66 & 1151396,1 & & \\
\hline 4609 & 70,33 & 6,63 & 1422099,6 & & \\
\hline 4612 & 80,25 & 6,67 & 974470,1 & & \\
\hline 5413 & 50,14 & 7,71 & 628530,1 & & \\
\hline 4703 & 107,73 & 6,30 & 385820,9 & & \\
\hline 4706 & 116,14 & 6,51 & 289574,4 & & \\
\hline 3509 & 59,94 & 6,24 & & 500449,5 & \\
\hline 4306 & 31,68 & 6,57 & & 610985,6 & \\
\hline 4713 & 139,75 & 6,70 & & 985924,6 & \\
\hline 3313 & 28,11 & 6,22 & & 1359899,4 & \\
\hline 3314 & 27,60 & 6,10 & & 1718615,1 & \\
\hline 4410 & 43,95 & 6,89 & & 2027211,0 & \\
\hline 4604 & 72,42 & 6,39 & 8464382,0 & 608745,4 & 0,07 \\
\hline 5504 & 51,81 & 7,39 & 13412492,0 & 1268738,5 & 0,09 \\
\hline 4607 & 71,55 & 6,52 & 5845420,0 & 886310,8 & 0,15 \\
\hline 4402 & 25,57 & 6,41 & 7761921,5 & 2455749,3 & 0,32 \\
\hline 4616 & 79,65 & 6,90 & 960945,4 & 350285,8 & 0,36 \\
\hline 3505 & 68,82 & 6,07 & 1196522,4 & 596468,0 & 0,50 \\
\hline 5503 & 50,20 & 7,14 & 928051,9 & 676122,4 & 0,73 \\
\hline 4503 & 48,73 & 6,45 & 636971,5 & 1232274,8 & 1,93 \\
\hline 2507 & 68,51 & 5,46 & 558369,5 & 1170234,0 & 2,10 \\
\hline 2307 & 17,20 & 5,00 & 1452911,5 & 3250842,0 & 2,24 \\
\hline 4401 & 44,72 & 6,20 & 429351,8 & 1398543,9 & 3,26 \\
\hline 3404 & 41,26 & 6,08 & 425473,2 & 1585518,4 & 3,73 \\
\hline 4412 & 28,45 & 6,81 & 567354,7 & 2822688,8 & 4,98 \\
\hline 3407 & 45,36 & 5,86 & 370131,6 & 1975343,1 & 5,34 \\
\hline 4403 & 29,15 & 6,52 & 249968,2 & 1357345,4 & 5,43 \\
\hline 3405 & 29,00 & 6,12 & 89651,5 & 1245062,1 & 13,89 \\
\hline
\end{tabular}

Mr (Relative mass): massa relativa.

pI: Ponto isoelétrico. 


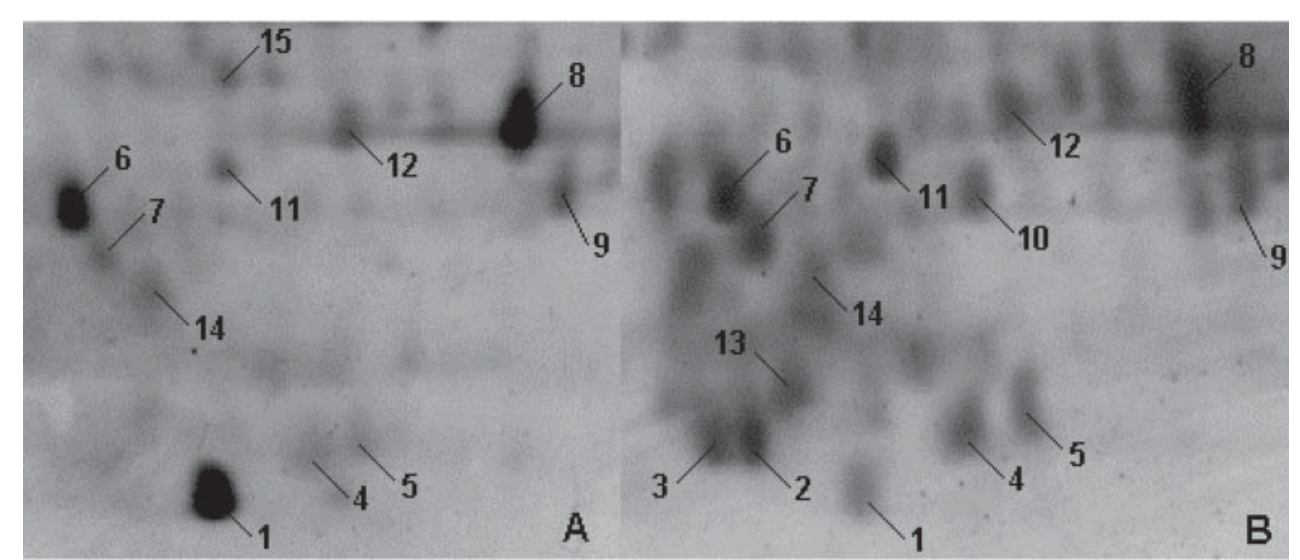

Figura 1 - Géis 2D-PAGE demonstrando spots diferencialmente expressos (seta). SSP (Sample Spot Protein) é número de identificação do spot no software PDQuest 8.0.1 (Bio-Rad). A- condição de $28^{\circ} \mathrm{C}$; Bcondição de $37^{\circ} \mathrm{C}$; 1 - SSP 4402; 2- SSP 3313; 3- SSP 3314; 4- SSP 4412; 5- SSP 3404; 6- SSP 3403; 7- SSP 4401; 8- SSP 5504; 9- SSP 5404; 10- SSP 4410; 11- SSP 4503; 12- SSP 5502; 13 - SSP 3405; 14- SSP 3408; 15- SSP 4504.

$37^{\circ} \mathrm{C}$, quando comparado a $25^{\circ} \mathrm{C}$ (PINEL et al., 2011). A ocorrência de 50 proteínas superexpressas foi detectada em $\boldsymbol{A}$. fumigatus, utilizando uma técnica mais sensível a 2D-DIGE (ALBRECHT et al., 2010). Tem sido demonstrado que a superexpresão de algumas proteínas em A. fumigatus, através de mutantes nulos, é necessária para a termotolerância, virulência e manutenção na natureza (BHABHRA et al., 2004).

Alguns genes essenciais para o crescimento a $37^{\circ} \mathrm{C}$ têm sido identificados em $\boldsymbol{C}$. neoformans (ROSA E SILVA et al., 2008; KRAUS et al., 2004), os quais estão relacionados com a virulência do patógeno. No fungo dimórfico $\boldsymbol{P}$. brasiliensis, foram encontrados genes superexpressos durante a transição de micélio para levedura (MONTEIRO et al., 2009; GARCIA et al., 2010), fato que está diretamente relacionado com a mudança de temperatura.

Proteínas como Ras1, a p21, Ste20 kinase, Cts1, Vph1, Tsa1, Mpk1, e a Ca2/calmodulin-dependent phosphatase calcineurin foram identificadas em $\boldsymbol{C}$. neoformans como sendo essenciais ou importantes ao crescimento em altas temperaturas (KRAUS et al., 2004). Recentemente, foi descrito, por meio da técnica de RDA, a expressão diferencial por $\boldsymbol{C}$. lamprauges do gene que codifica a enolase, sendo que a exposição à temperatura elevada $\left(37^{\circ} \mathrm{C}\right)$ possivelmente esteja associada à superexpressão dessa proteína (SILVA et al., 2012).

A identificação dessas proteínas poderá auxiliar na descoberta de características relacionadas à patogênese da doença, na regulação térmica, na descoberta de novos diagnósticos e tratamentos e vacinas.

\section{CONCLUSÃO}

Sugere-se que C. lamprauges produza um perfil de proteínas relacionadas à termorregulação para se adaptar ao ambiente do hospedeiro, sendo necessários outros estudos utilizando ferramentas moleculares para identificá-las e que possam contribuir para melhor entendimento da patogenia e virulência do fungo.

\section{AGRADECIMENTOS}

À fundação de Amparo à Pesquisa do Estado de Mato Grosso (FAPEMAT) e ao Conselho Nacional de desenvolvimento Científico e Tecnológico (CNPq), pelo apoio financeiro.

\section{REFERÊNCIAS}

ALBRECHT, et al. Integrative analysis of the heat shock response in Aspergillus fumigatus. BMC genomics, v.11, n.1, p.1-17, 2010. Disponível em: <http://www.biomedcentral.com/14712164/11/32>. Acesso em: jul. 2013. doi: 10.1186/1471-216411-32.

BHABHRA, R. et al. Disruption of the Aspergillus fumigatus gene encoding nucleolar protein CgrA impairs thermotolerant growth and reduces virulence. Infection and Immunity, v.72, n.8, p.4731-4740, 2004.Disponível em: <http://www.ncbi.nlm.nih.gov/ pmc/articles/PMC470587/>. Acesso em: jan. 2013. doi: 10.1128/ IAI.72.8.4731-4740.2004

BJELLQVIST, B. et al. Micropreparative two-dimensional electrophoresis allowing the separation of samples containing milligram amounts of proteins. Electrophoresis, v.14, n.1, p.1375 1378, 1993. Disponível em: <http://onlinelibrary.wiley.com/ doi/10.1002/elps.11501401212/pdf $>$. Acesso em: dez. 2011. doi: 10.1002/elps.11501401212. 
BOABAID, F. M. et al. Conidiobolomicose em ovinos no Estado de Mato Grosso. Pesquisa Veterinária Brasileira, v.28, n.1, p.77-81, 2008. Disponível em: <http://dx.doi.org/10.1590/S0100736X2008000100012>. Acesso em: nov. 2011. doi: 10.1590/ S0100-736X2008000100012.

BRADFORD, M. M. A rapid and sensitive method for the quantitation of microgram quantities of protein utilizing the principle of protein-dye binding. Analytical Biochemmistry, v.72, p.248-254, 1976. Disponível em: <http://www.ciens.ucv.ve:8080/ generador/sites/labbioqgen/archivos/Bradford\%201976.pdf>. Acesso em: dez. 2011.

CARRIGAN, M. J. et al. Ovine nasal zygomycosis caused by Conidiobolus incongruus. Australian Veterinary Journal, v.69, n.10, p.237-240, 1992. Disponível em: <http://onlinelibrary.wiley. com/doi/10.1111/j.1751-0813.1992.tb09869.x/abstract>. Acesso em: dez. 2012. doi: 10.1111/j.1751-0813.1992.tb09869.x.

DISMUKES, W. E. et al. Clinical mycology. New York: Oxford University, 519 p., 2003.

GADGILE, D. P.; CHAVAN, A. M. Impact of temperature and relative humidity on development of Aspergillus flavus rot of mango fruit. Recent Research in Science and Technolgy, v.2, n.3, p.48-49, 2010. Disponível em: <http://recentscience.com/index. php/rrst/article/view/2413>. Acesso em: jan. 2013.

GALDOS-RIVEROS, A. C. et al. Proteômica: novas fronteiras na pesquisa clínica. Enciclopédia Biosfera, v.6, n.11, p.1-24, 2010. Disponível em: <http://www.conhecer.org.br/enciclop/2010c/ proteonica.pdf $>$. Acesso em: jan. 2012.

GARCÍA, A. M. et al. Gene expression analysis of Paracoccidioides brasiliensis transition from conidium to yeast cell. Medical Mycology, v.48, n.1, p.147-154, 2010. Disponível em: <http:// informahealthcare.com/doi/abs/10.3109/13693780903055673>. Acesso em: jan. 2013. doi: 10.3109/13693780903055673.

KIMURA, M. et al. Disseminated human conidiobolomycosis due to Conidiobolus lamprauges. Journal of Clinical Microbiology, v.49, n.2, p.752-756, 2011. Disponível em: <http://jcm.asm. org/content/49/2/752>. Acesso em: dez. 2012. doi: 10.1128/ JCM.01484-10.

KRAJAEJUN, T. et al. Effect of temperature on growth of the pathogenic oomycete Pythium insidiosum. Southeast Asian Journal of Tropical Medicine and Public Health, v.41, n.6, p.1462-1466, 2010. Disponível em: <http://www.tm.mahidol. ac.th/seameo/2010-41-6/26-4876.pdf>. Acesso em: dez. 2012.

KRAUS, P. R. et al. Identification of Cryptococcus neoformans temperature-regulated genes with a Genomic-DNA microarray. Eukaryotic Cell, v.3, n.5, p.1249-1260, 2004. Disponívelem: $<$ http://ec.asm.org/content/3/5/1249.full>. Acesso em: dez. 2011. doi: 10.1128/EC.3.5.1249-1260.2004.

LAEMMLI, U. K. Cleavage of structural proteins during the assembly of the head of bacteriophage T4. Nature, v.227, p.680685, 1970. Disponível em: <http://www.nature.com/nature/ journal/v227/n5259/abs/227680a0.html>. Acesso em: dez. 2011. doi: $10.1038 / 227680 \mathrm{a} 0$

MONTEIRO, J. P. et al. Genomic DNA microarray comparison of gene expression. Patterns in Paracoccidioides brasiliensis mycelia and yeasts in vitro. Microbiology, v.155, p.2795-2808, 2009. Disponível em: <http://mic.sgmjournals.org/content/155/8/2795. long>. Acesso em: jan. 2013. doi 10.1099/mic.0.027441-0.
O'FARRELL, P. H. High resolution two-dimensional electrophoresis of proteins. Journal of Biological Chemistry, v.250, n.10, p.4007-4021, 1975. Disponível em: <http://www.jbc. org/content/250/10/4007.long >.Acessoem: dez. 2011.

PAULA, D. A. J. et al. Molecular characterization of ovine zygomycosis in Central Western Brazil. Journal of Veterinary Diagnostic Investestigation, v.22, n.2, p.274-277, 2010. Disponível em: <http://vdi.sagepub.com/content/22/2/274.long>. Acesso em: jan. 2012. doi: 10.1177/104063871002200220.

PINEL, C. et al. Comparative proteomic profiles of Aspergillus fumigatus and Aspergillus lentulus strains by surface-enhanced laser desorption ionization time-of-flight mass spectrometry (SENDI-TOFMS). BMC Microbiology, v.11, n.172, p.1-10, 2011. Disponível em: $<$ http://www.biomedcentral.com/1471-2180/11/172>. Acesso em: jan. 2013.doi: 10.1186/1471-2180-11-172.

RABILLOUD, T. Use of thiourea to increase the solubility of membrane proteins in two-dimensional electrophoresis. Electrophoresis, v.19, n.5, p.758-760, 1998. Disponível em: $<$ http://onlinelibrary.wiley.com/doi/10.1002/elps.1150190526/ pdf $>$. Acesso em: dez. 2011. doi: 10.1002/elps.1150190526.

RIBEIRO, C. S. A influência térmica na regulação da expressão gênica e sua ação na dinâmica das membranas celulares. Revista da Biologia, v.4, p.6-9, 2010. Disponível em: <http://www. ib.usp.br/revista/volume4>. Acesso em: dez. 2012. doi: 10.7594/ revbio.04.02.

RIBES, J. A. et al. Zygomycetes in humandisease. Clinical Microbiology Reviews, v.13, n.2, p.236-301, 2000. Disponível em: <http://cmr.asm.org/content/13/2/236.full $>$. Acesso em: jan. 2012. doi: 10.1128/CMR.13.2.236-301.2000.

ROSA E SILVA, L. K. et al. Identification of novel temperatureregulated genes in the human pathogen Ctypypcoccus neoformans using representational difference analysis. Research in

Microbiology, v.159, p.221-229, 2008. Disponível em: <http:// www.sciencedirect.com/science/article/pii/S092325080700263X>. Acesso em: nov. 2012. doi: 10.1016/j.resmic.2007.12.2006.

SHAH, P. A.; PELL, J. K. Entomopathogenic fungi as biological control agents. Applied Microbiology and Biotechnology, v.61, n.5-6, p.413-423, 2003. Disponível em: <http://link.springer.com/ article/10.1007\%2Fs00253-003-1240-8?LI=true >. Acesso em: jan. 2013.doi: $10.1007 / \mathrm{s} 00253-003-1240-8$

SILVA, J. A. G. et al. Genes termorregulados diferencialmente expressos em Conidiobolus lamprauges. Ciência Rural, v.42, p.1610-1613, 2012. Disponível em: <http://dx.doi.org/10.1590/ S0103-84782012005000064>. Acesso em: nov. 2012. doi: $10.1590 / \mathrm{S} 0103-84782012005000064$

WAINGANKAR, V. M. et al. A new thermophilic species of Conidiobolus from India. Mycopathologia, v.165, n.3, p.173-177, 2008. Disponível em: <http://link.springer.com/content/pdf/10.10 07\%2Fs11046-007-9088-6>. Acesso em: jan. 2013. doi: 10.1007/ s11046-007-9088-6.

WALKER, G. M.; WHITE, N. A. Introduction to fungal physiology. In: KAVANAGH, K. Fungi: biology and aplications. Chichester, UK: John Wiley \& Sons, p. 1-34, 2005.

WESTERMEIER, R.; NAVEN, T. Proteomics in practice: a laboratory manual of proteome analysis. Weinheim, Germany: Wiley-VCH, 310 p., 2002.

WINTERS, M. S. et al. Histoplasma capsulatum proteome response to decreased iron availability. Proteome Science, v.6, n.36, p.1-13, 2008. Disponível em: $<$ http://www.proteomesci.com/content/6/1/36>. Acesso em: dez. 2011. doi: 10.1186/1477-5956-6-36. 